\section{MEDICAL DEVELOPMENTS IN FIJI}

AULL report of the address given by Dr. V. W. T. McGusty, director of medical services, Fiji, to the Legislative Council on plans for the future of medicine in Fiji and its neighbouring islanid groups is given in the Fiji Times and Herald of February 24, 1944 ; and a leading article in the journal warmly commends these plans.

Dr. McGusty also gives in his address a very inter. esting history of medical progress in that part of the world. It is clear from what he says, from his discussions of his plans with the Colonial Office, from the approval of the plans by the Legislative.Council, and from the discussions of the financial requirements of the reorganization proposed, that Fiji is going to incorporate in its medical services the medical developments which are now being organized in the Western world, and that it has both the ability and the personnel to make them as efficient as they are anywhere. The existing medical services are not to be thought of as being in any way primitive. The existing Central Medical School and the Nurses Training Centre and the Central Leper Hospital are joint services in which the New Zealand Government and the American administration of Samoa take part; and the Western Pacific Territories and the Australian Government are also concerned with some of them. All these services are discussed in Council Papers Nos. 2, 3 and $18^{*}$.

The difficulties of the medical man in these island groups, his Odysseys in conditions of bad weather and difficult landings in surf-boats, and the remarkably efficient help which the European or American practitioner gets from the keen and well trained Fijian medical practitioners, are described by Dr. McGusty in this address and also in an article which he contributes to the Native Medical Practitioner (Vol. 3, No. 3 ; Sept. 1941), which is the journal of the Central Medical School, Suva. Other articles in this journal by native medical men and nurses show that Dr. McGusty's praise of them is well founded. There is an eagerness about their writing, and a desire to relieve suffering, which indicates a refreshing and noble realization of their mission. "I hope, sir," one of them writes in his report on seven weeks work on the island of Tongoa, "that you will enjoy reading this brief account of my first start in the New Hebrides." "Hoping," he concludes, "that all the students are working hard at their studies, and with best regards to you, sir, and all the students, your obedient N.M.P. and old student, A. K. Manulevu." What teacher would not be proud to receive such a letter and to do all he can to save such a race from extinction?

For it amounts to that-no less. "If serious infectious diseases," Dr. MeGusty says, "such as malaria, can be kept out of Fiji, the Fijian race may survive." While tuberculosis is still the greatest single disease problem, the danger of the introduction of other diseases which can wipe out populations has always been a menace to Fijian medical care. The geographical position of Fiji renders it likely to become an important junction for civil air traffic after the War, so that its health problems will have more than a local interest. New Zealand is also extending

* Legislative Council, Fiji. Council Paper No.18: Annual Report of the Medical Department for 1942. Pp. 24. Council Paper No. 2. Post War Reconstruction: Fiji and Western Pacific. Council Paper No. 3. Report on Public Health and Medical Services in the Colony of Fiji. (Suva: Government Printer, 1943-44.) its medical organization and desires closer co-operation with Fiji and the Western Pacific.

Fiji was discovered by Tasman in 1643 and, until the first Europeans arrived at the end of the eighteenth century, the infectious diseases of Western civilization were unknown to Fijians. After 1790, native folk-Iore and other sources spoke of epidemics which took toll of a population of some 250,000 , but this number had fallen fifty years later to 150,000 . Protestant and Catholic missionaries probably introduced diseases, but they were, says Dr. McGusty, the only people who could control them or alleviate suffering, and full credit must be given to them for their work. The cotton boom brought more Europeans and more disease. The late King Cakobau, a very wise ruler, unified the country and led it into the care of Great Britain, to the colonizing power of which Dr. McGusty pays a warm tribute. The Fijian race was nearly wiped out in 1875 by an epidemic of measles which killed 40,000 people. The risk of the introduction of further infectious diseases was, however, vigorously combated by Sir William MacGregor, who instituted strict quarantine barriers, the vaccination of the people and the training of native youths to vaccinate and to practise medicine among their own people. This policy was carried on by Drs. Corney, Lynch and Montague.

The fight against infant mortality, which became serious enough to threaten the progress of the native races, was taken up in earnest, and further increase was checked by Miss Anderson's scheme for training Fijian girls as midwives and nurses. Miss M. L. Lea, principal matron of the Central Nursing School, tells us, in Council Paper No. 18, the history of this school and of its nursing services. Native methods of childbirth and artificial feeding are described in the Native Medical Practitioner (Vol. 3, No. 3; 1941), and from these accounts it appears that babies fed entirely on coco-nut prepared in various ways until they are more than eighteen months old may be as healthy as those that are breast-fed. Western methods are, however, rapidly effecting desirable improvements. Dr. McGusty, in his address, pays a high tribute to the work of the experts sent into these island groups by the Rockefeller Foundation, and in particular to the work of Dr. S. M. Lambert. Valuable also has been the opening to other island groups, by courtesy of the New Zealand Government and other authorities, of the Leper Hospital at Makongai. Half the deaths in this hospital in 1942 were Indians, a fact which may be considered together with the fact that the Indian population had, by 1942 , risen to within 4,000 of the Fijian, and is expected to overtake and surpass it.

It is clear that the Government's plan to unify the medical services of all these island groups under the control of Fiji will do much to ensure the success of its scheme of improvement. The participation of New Zealand will be invited, and a director-general of public health and medical services for Fiji and the Western Pacific would be appointed, with a deputy director. The scheme includes the building, on a new site with adequate transport and facilities for expansion, of a new central hospital in Fiji of not less than 300 beds, an obstetric hospital of not less than 20 beds, a medical school for 80 medical students including 8 dental students, a nursing school for 150 students and a public health centre. The existing Suva Hospital, which is inadequate in size and equipment, could be altered to accommodate the 
Public Health Centre and the administration of the Joint Pacific Public Health Authority and of the Medical Department of Fiji. In addition, it is proposed to use the buildings of the existing Colonial War Memorial Hospital, erected in 1923 to commemorate the fallen in the War of 1914-18, as a new and wellequipped isolation hospital. There will also be four regional hospitals, and the provincial hospitals will be improved. Modern research laboratories, built in 1936 with the help of the Rockefeller Foundation and of Lord Trent, are also available and adequate for present needs.

of special general interest in view of the precautions which are being taken, all over the world, against the spread of disease in these days of fast transport and aerial travel, are Dr. McGusty's remarks about malaria. Malaria-carrying mosquitoes did not reach Fiji even in the days of sailing ships, although no special precautions were taken to prevent their entry. Dr. MeGusty suggests that the southeast trade winds delayed the ships and washed their decks with salt spray, and also that their water-casks were always filled from fast-running streams in which mosquito larvæ did not develop. But the present War has brought an immense volume of traffic by sea and air, and it is a great tribute to the British and United States navy and army authorities that the precautions they have taken have so far kept malaria out of Fiji. How fatal to Fijians its entry might be, and how vital these precautions are, will be realized by those who have read the note in Nature of May 20,1944, p. 625, on the importance of all human parasites in times of war, and on the very serious results which may follow their attack on populations which are not accustomed to them.

Council Paper No. 3, which is a report on the public health and medical services of Fiji made by Dr. Watt, director general of health, New Zealand, and Miss Lambie, director of nursing, New Zealand (the Watt-Lambie Report), illustrates the co-operation between Fiji and New Zealand which the Legislative Council of Fiji wishes to encourage. This report is not merely a report on the health of Fiji ; it is also a valuable essay in modern public health practice. Plague and smallpox are, it points out, constant menaces to countries in the Pacific. They can be combated by the quarantine system and measures for rat control recommended by the report and by vaccination for smallpox. The importance of keeping out anopheline mosquitoes is emphasized. The other quarantinable Fijian diseases are yellow fever, cholera and typhus. The recent discovery of the efficacy of $D D T$ as a means of killing the lice which transmit typhus and its successful application to large numbers of people in Naples recently should greatly assist the control of this disease in Fiji as well as elsewhere in the world, if, indeed, it does not check its ravages completely. The principal infectious diseases in Fiji are tuberculosis, typhoid fever, dysentery, diphtheria (which is not a major problem) and yaws and hook-worm (which are being well handled).

Tubereulosis is a serious problem in all native races and this report recommends mass miniature radiography, as well as the other measures usually used for its control. Local housing standards are usually good, but it is feared that tuberculosis may increase as the number of town dwellers increases. The pasteurization of milk in the larger communities, or in some places the boiling of it, are recommended, and this should help in the control of tuberculosis as well as that of typhoid and some other illnesses. The control of typhoid and dysentery depends upon safe milk, water and food and on efficient sanitation and general cleanliness. Better supervision of meat supplies and of milk production and improvement of housing, drainage and sewage disposal are required in some areas. The report discusses in some detail the organization and staff of the medical department, the maternal and child-welfare services and the existing hospital services (reports on the last-named constitute an appendix to the report). Other sections of the report deal with the medical, dental and nursing services and with medical and health education. The criticisms of these are, in the main, met by the scheme of reorganization outlined above.

The authors of the report think that Fiji will become a natural centre for medical research and education for the various island groups of the South Pacific. Its excellent climate and freedom from malaria and other tropical diseases should help this development.

Everyone will wish success to the medical authorities of Fiji in the carrying out of this beneficent scheme. The peoples of these island groups deserve all that we can do for them when, before very long, their sunny land will be freed from the shadow which has recently menaced their future. G. IAAPAGE.

\section{FEDERAL ACTIVITY IN AMERICAN EDUCATION}

$\mathrm{T}$ is not easy, for a non-American, to understand why each of the forty-eight States of America should be educationally autonomous, and why therefore it is difficult for anyone to speak for American education as a whole. This is but one aspect of the opposition between Federal Government and State rights - a matter incomprehensible to a person who is unacquainted with the broad lines of American history and has never travelled in the United States. But war is a national effort, and must be conducted by the nation, in this case with powerful collateral effects upon the forty-eight educational systems. Thus the United States Office of Education at Washington, headed by the U.S. Commissioner of Education, is extremely active, and by the use of the funds provided by the Federal Government for educational purposes is able to promote the ends of a nation at war. So much is made clear by the Annual Reports of the U.S. Office of Education 1941-2 and 1942-3, by the pamphlet entitled "Federal Government Funds for Education 1940-1 and 1941-2", and by the official bi-weekly journal Education for Victory, which replaces School Life for the duration of the War, and which is specially addressed to all American youth.

Among the war-time causes aided by the U.S. Office of Education agriculture takes a very prominent place, followed by vocational education, vocational rehabilitation, national defence training, library service, adjustment of college curricula to meet wartime needs, teacher personnel problems, not to speak of a long list of less important subjects.

Another way in which the U.S. Office of Education conveniently speaks for America as a nation is exemplified by pamphlets entitled "Inter-American Education : A Curriculum Guide", and "Education in Cuba". The former represents a concerted effort on the part of the U.S. Olfice of Education to establish a plan for making the study of the other American 